\title{
The total ozone field separated into meteorological regimes - Part II: Northern Hemisphere mid-latitude total ozone trends
}

\author{
R. D. Hudson ${ }^{1}$, M. F. Andrade ${ }^{2}$, M. B. Follette ${ }^{1}$, and A. D. Frolov ${ }^{3}$ \\ ${ }^{1}$ Department of Atmospheric and Oceanic Science, University of Maryland, College Park, MD 20742-2425, USA \\ ${ }^{2}$ Atmospheric Physics Laboratory, Campus Universitario Cota-Cota, Calle 27, Universidad Mayor de San Andres, La Paz, \\ Bolivia \\ ${ }^{3}$ STG, Inc., 11710 Plaza America Drive, Reston, VA, USA
}

Received: 7 June 2006 - Published in Atmos. Chem. Phys. Discuss.: 11 July 2006

Revised: 13 October 2006 - Accepted: 8 November 2006 - Published: 15 November 2006

\begin{abstract}
Previous studies have presented clear evidence that the Northern Hemisphere total ozone field can be separated into distinct regimes (tropical, midlatitude, polar, and arctic) the boundaries of which are associated with the subtropical and polar upper troposphere fronts, and in the winter, the polar vortex. This paper presents a study of total ozone variability within these regimes, from 1979-2003, using data from the TOMS instruments. The change in ozone within each regime for the period January 1979-May 1991, a period of rapid total ozone change, was studied in detail. Previous studies had observed a zonal linear trend of $-3.15 \%$ per decade for the latitude band $25^{\circ}-60^{\circ} \mathrm{N}$. When the ozone field is separated by regime, linear trends of $-1.4 \%, 2.3 \%$, and $3.0 \%$, per decade for the tropical, midlatitude, and polar regimes, respectively, are observed. The changes in the relative areas of the regimes were also derived from the ozone data. The relative area of the polar regime decreased by about $20 \%$; the tropical regime increased by about $10 \%$ over this period. No significant change was detected for the midlatitude regime. From the trends in the relative area and total ozone it is deduced that $35 \%$ of the trend between $25^{\circ}$ and $60^{\circ} \mathrm{N}$, from January $1979-$ May 1991 is due to movement of the upper troposphere fronts. The changes in the relative areas can be associated with a change in the mean latitude of the subtropical and polar fronts within the latitude interval $25^{\circ}$ to $60^{\circ} \mathrm{N}$. Over the period from January 1979 to May 1991 , both fronts moved northward by $1.1 \pm 0.2$ degrees per decade. Over the entire period of the study, 1979-2003, the subtropical front moved northward at a rate of $1.1 \pm 0.1 \mathrm{de}-$ grees per decade, while the polar front moved by $0.5 \pm 0.1$ degrees per decade.
\end{abstract}

Correspondence to: R. D. Hudson

(hudson@atmos.umd.edu)

\section{Introduction}

In a previous paper, Hudson et al. (2003), presented clear evidence that the Northern Hemisphere total ozone field can be separated into distinct regimes, the boundaries of which are associated with the subtropical and polar upper troposphere fronts, and in the winter, the polar vortex. These regimes were defined as: (1) the arctic regime - within the polar vortex, (2) the polar regime - between the polar front and the polar vortex, or when the latter is not present, the pole, (3) the midlatitude regime - between the subtropical and polar fronts, and (4) the tropical regime - between the equator and the subtropical front. The subtropical and polar fronts are associated with the subtropical and polar jet streams, and have mean latitudes of about $30^{\circ}$ and $60^{\circ} \mathrm{N}$, respectively. It should be noted that the mean position of the subtropical front as defined here, is not the same as the position of the maximum of the mean westerly tropospheric zonal winds, which is also sometimes referred to as the subtropical front (Bluestein, 1993). The positions of the subtropical and polar fronts defined in Hudson et al. (2003) vary on a daily basis as the Rossby waves meander about their mean latitudes. Finally, these fronts should not be confused with the cold and warm fronts associated with cyclonic flow close to the surface. Hudson et al. (2003) showed, using rawinsonde measurements, that the tropical, midlatitude, and polar regimes were identified with distinct tropopause heights over a large latitude range. In addition, in any month, a unique total ozone value and a distinct ozone profile shape could be assigned to each of these three regimes.

The definition of "mid-latitude" used in previous studies has varied. WMO (1999) and Staehelin et al. (2001) used the interval from $25^{\circ}$ to $60^{\circ} \mathrm{N}$, while Fioletov et al. (2002) and WMO (2003) used the interval from $35^{\circ}$ to $60^{\circ} \mathrm{N}$. In this paper we have chosen the latitude range from $25^{\circ}$ to $60^{\circ} \mathrm{N}$. Previous studies of the variability of total ozone and of

Published by Copernicus GmbH on behalf of the European Geosciences Union. 
the ozone profiles at midlatitudes (Harris et al., 1997, 1998; WMO, 1999; Staehelin et al., 2001) have centered on zonal averages over specific latitude bands. However, because the mean total ozone and the ozone profile are almost constant within a regime, a zonal average will depend on the relative areas of the respective regimes within the latitude range of the zone. Thus, for example, one can envision a long-term change in the zonal mean total ozone that is brought about by a long-term change in the relative areas of the regimes alone.

The total ozone archived data sets used in this paper are the Version 8 level-3 hierarchical data format product from the TOMS (Total Ozone Mapping Spectrometer) instruments (McPeters et al., 1996; Wellemeyer et al., 2004). The level3 data set is an average ozone value on a 1-degree latitude by 1.25 degrees longitude grid. At this time three data sets are available, those from the Nimbus-7 satellite (November 1978-May 1993), the Meteor-3 satellite (August 1992-November 1994), and the Earth Probe satellite, (September 1996-December 2003), leaving a gap in the data record between December 1994 and August 1996. Although the Nimbus-7 and Meteor-3 time periods overlap, Nimbus7 data was used whenever available. The unit used within this paper for the total (column) ozone is the Dobson Unit (1 DU $=1 \mathrm{~m}$ atm cm, or $2.69 \times 10^{16}$ molecules $\mathrm{cm}^{-2}$ ).

This paper examines the long-term change of ozone between 1979 and 2003 within the tropical, midlatitude, polar, and arctic meteorological regimes as defined above. It is divided into four sections. In Sect. 2, the method used to define the boundaries between the regimes is presented. The results of the analysis are given in Sect. 3. The summary and conclusions of the paper are given in Sect. 4.

\section{The regime boundaries}

For every day that TOMS data was available, total ozone values for the subtropical and polar boundaries were derived using the method described in Hudson et al. (2003). A contour program for these two boundary values was then used to obtain the positions of the fronts on the total ozone field for that day. The polar vortex boundary was obtained from the position of the maximum gradient in potential vorticity (PV) on the $550 \mathrm{~K}$ isentropic surface. This dataset was obtained from the NCEP/NCAR (National Centers for Environmental Prediction/National Center for Atmospheric Research) reanalysis (Kalnay et al., 1996). Figure 1a shows the TOMS total ozone field for 11 March 1990, with the ozone contours representing the subtropical and polar boundaries, and the arctic boundary obtained from the PV field for this day. Figure $1 \mathrm{~b}$ shows the one-degree zonally averaged total ozone within each regime, and for the unclassified data. As noted in Hudson et al. (2003) and seen in Fig. 1b, each regime has a distinct range of ozone values that do not overlap. However, the total ozone within each regime shows that there is a small dependence (relative to the unclassified data) of total ozone with latitude. This latitude dependence is greatest in the winter months, and is at a minimum in the summer months. Because trends in total ozone are of the order of few percent, small errors in the determination on the location of the upper-level fronts could introduce relatively large errors in the determination of long term area trends. For that reason, the latitude dependence of total ozone must be taken into account when determining the location of the upper-level fronts for trend analysis. It should be stressed, however, that the total ozone trends within each regime are not sensitive to small errors in the determination of the exact locations of the upper-level fronts.

A new method was developed in order to allow the boundaries to take into account any latitude dependence. The daily boundary values from Hudson et al. (2003) were used as a first guess to separate the total ozone into regimes. Next, onedegree zonal averages were calculated for each regime, as seen in Fig. 1b. New subtropical boundary values were computed by taking the average of the tropical and midlatitude total ozone at each latitude where they were both present. Similarly, the polar boundary was calculated by taking the average of the midlatitude and polar total ozone. The new boundary values are displayed as black stars on Fig. 1b. The total ozone field was then separated using these new latitudinally dependent boundaries. The process was then repeated with the new boundary values. The relative area of a regime is the area of a regime divided by the total area between $25^{\circ}$ and $60^{\circ} \mathrm{N}$. Convergence was reached when the change in the relative area of each regime, from one iteration to the next, was less than $5 \%$. The $5 \%$ convergence criteria was chosen based on the spatial resolution of the TOMS data, $1^{\circ}$ latitude by $1.25^{\circ}$ longitude. In each iteration, any change in the area of a particular regime will have a minimum value given by the area of one pixel at each one-degree latitude band, which varies from $2-4 \%$. The final boundaries, after iteration, are plotted on Fig. 1c. It must be stressed that these ozone boundaries were obtained on a daily basis.

Using the daily values, the mean monthly relative area was obtained for each regime, for the latitude interval $25^{\circ}-60^{\circ} \mathrm{N}$. The standard deviation, persistence, and the standard error of the mean were then calculated for each month. Table 1 gives the climatalogical mean monthly relative area, the standard error of the mean, and the atmopsheric persistence in days for the tropical, midlatitude, and polar regimes, for the period 1979-2003. The atmospheric persistence is defined here as $(1+q) /(1-q)$ where $q$ is the lag-1 autocorrelation. The atmospheric persistence is close to three days, typical of meteorological parameters.

A fundamental assumption in our method is that total ozone acts as a dynamical tracer on synoptic timescales (Danielsen et al., 1970; Wohltmann, 2005). This assumption is valid in the absence of chemistry occurring on timescales shorter than dynamics. Therefore, because our boundaries are calculated on a daily basis, they are subject to changes 

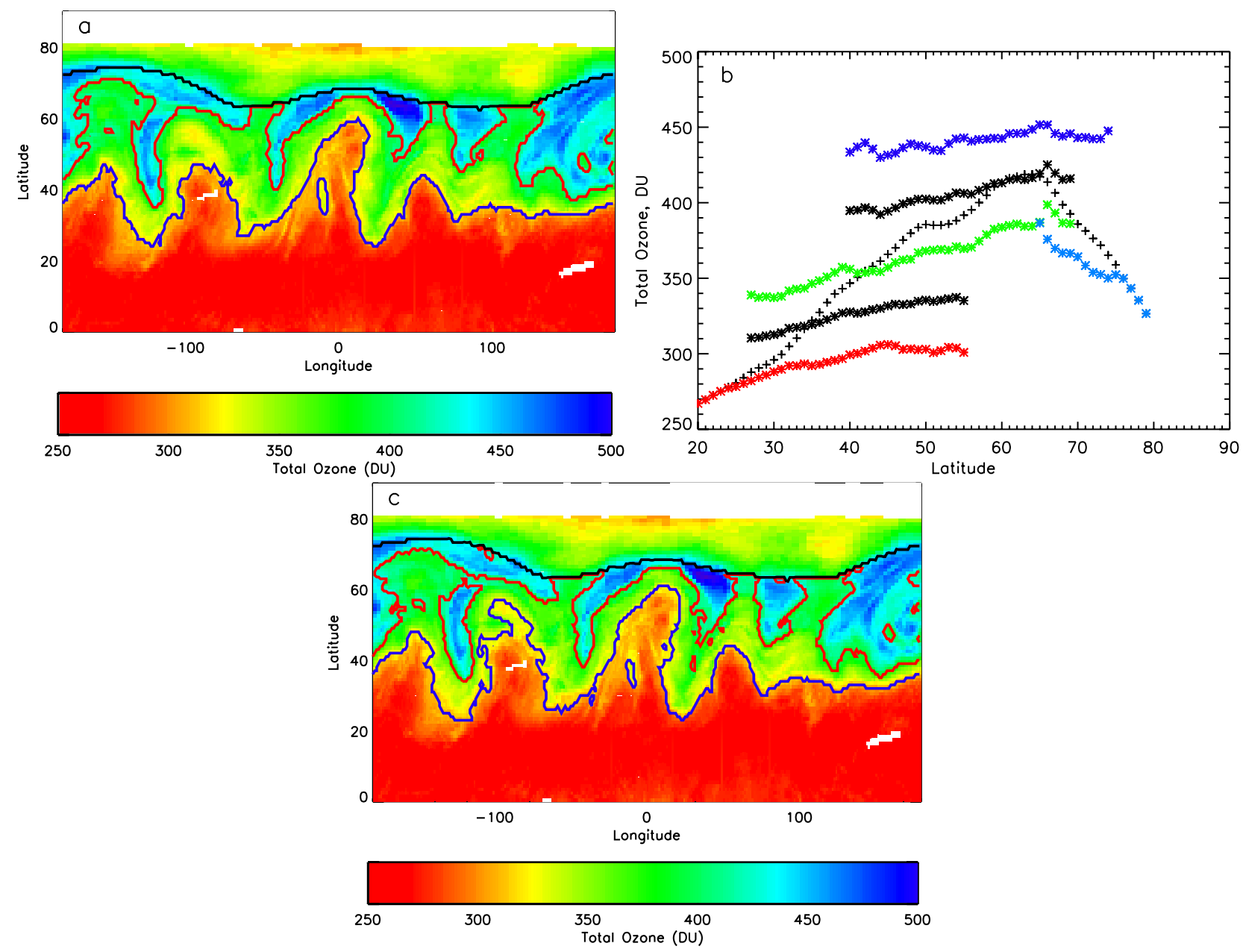

Fig. 1. (a) TOMS total ozone field for 11 March 1990. The subtropical (blue line), polar (red line), and polar vortex (black line) boundaries derived by Hudson et al. (2003) are also plotted. (b) The one-degree zonally averaged total ozone within the tropical (red stars), midlatitude (green stars), polar (blue stars), and arctic (light blue stars) regimes for 11 March 1990. The unclassified data is shown as black pluses. The new boundary values calculated by taking the average of neighboring regimes are shown as black stars. (c) Same as (a), except with the boundaries after the iteration procedure described in the text.

in ozone chemistry on timescales shorter than a day. However, in the lower stratosphere, the photochemical lifetime of ozone is of the order of several weeks (Brasseur and Solomon, 1984). This is large compared to the timescale of transport, approximately one day (Salby and Callaghan, 1993). For this reason, ozone in this region, as well as total ozone, is considered to be a dynamical tracer on the timescale of a few days (Wohltmann et al., 2005).

An experiment was carried out to test whether a latitudinally dependent chemical trend in ozone over time would affect the placement of the regime boundaries. Two runs from NASA Goddard Space Flight Center's (GSFC) 3-D Full Chemistry and Transport Model (FCTM, Douglass et al., 1996) were used. The transport in this model is calculated off-line, such that the chemical constituents have no influence over the model dynamics. The resolution of the model was $4^{\circ}$ longitude by $5^{\circ}$ latitude, with 28 levels in the vertical. Both heterogeneous, as well as gas-phase chemistry are included. The wind fields were derived using data from the NASA GSFC Data Assimilation Office (DAO). The first run was from February 1973 to December 2022, with observed aerosol and source gas concentrations The second run was from January 1979 to December 2010, and was the same as the first, except source gases were held to their 1979 value. The actual time period used for this experiment was 19832003. The constant source gas run required several years of spin-up time (A. Douglass, personal communication), and corresponding time periods were desired. The positions of the meteorological upper-troposphere fronts should be the same in both runs. The ozone boundaries were then calculated for both runs using the method described above, and the relative areas calculated from 1983-2003. There was no 
Table 1. Mean relative area, error of the mean, and persistence.

\begin{tabular}{llllllllll}
\hline & \multicolumn{3}{c}{ Tropical Regime } & \multicolumn{3}{c}{ Midlatitude Regime } & \multicolumn{3}{c}{ Polar Regime } \\
Month & $\begin{array}{l}\text { Mean } \\
\text { area }\end{array}$ & $\begin{array}{l}\text { Error of } \\
\text { the mean }\end{array}$ & $\begin{array}{l}\text { Persistence } \\
\text { (Days) }\end{array}$ & $\begin{array}{l}\text { Mean } \\
\text { area }\end{array}$ & $\begin{array}{l}\text { Error of } \\
\text { the mean }\end{array}$ & $\begin{array}{l}\text { Persistence } \\
\text { (Days) }\end{array}$ & $\begin{array}{l}\text { Mean } \\
\text { area }\end{array}$ & $\begin{array}{l}\text { Error of } \\
\text { the mean }\end{array}$ & $\begin{array}{l}\text { Persistence } \\
\text { (Days) }\end{array}$ \\
\hline Jan & 0.39 & 0.02 & 2.8 & 0.43 & 0.02 & 3.8 & 0.16 & 0.01 & 4.5 \\
Feb & 0.37 & 0.02 & 3.4 & 0.43 & 0.02 & 3.9 & 0.17 & 0.01 & 3.4 \\
March & 0.35 & 0.02 & 3.0 & 0.45 & 0.02 & 3.8 & 0.18 & 0.02 & 4.6 \\
April & 0.32 & 0.02 & 3.4 & 0.48 & 0.02 & 4.1 & 0.19 & 0.01 & 4.0 \\
May & 0.28 & 0.02 & 3.5 & 0.51 & 0.02 & 4.0 & 0.21 & 0.01 & 3.4 \\
June & 0.32 & 0.02 & 4.1 & 0.50 & 0.02 & 4.4 & 0.18 & 0.01 & 3.4 \\
July & 0.34 & 0.02 & 3.1 & 0.52 & 0.02 & 3.6 & 0.14 & 0.01 & 3.8 \\
Aug & 0.35 & 0.02 & 3.3 & 0.55 & 0.02 & 3.2 & 0.11 & 0.01 & 2.5 \\
Sep & 0.40 & 0.02 & 3.4 & 0.49 & 0.02 & 3.6 & 0.11 & 0.01 & 2.6 \\
Oct & 0.42 & 0.02 & 2.5 & 0.44 & 0.02 & 2.9 & 0.11 & 0.01 & 2.7 \\
Nov & 0.43 & 0.02 & 2.9 & 0.42 & 0.02 & 3.1 & 0.12 & 0.01 & 3.4 \\
Dec & 0.39 & 0.02 & 2.8 & 0.43 & 0.02 & 3.0 & 0.14 & 0.01 & 4.5 \\
\hline
\end{tabular}
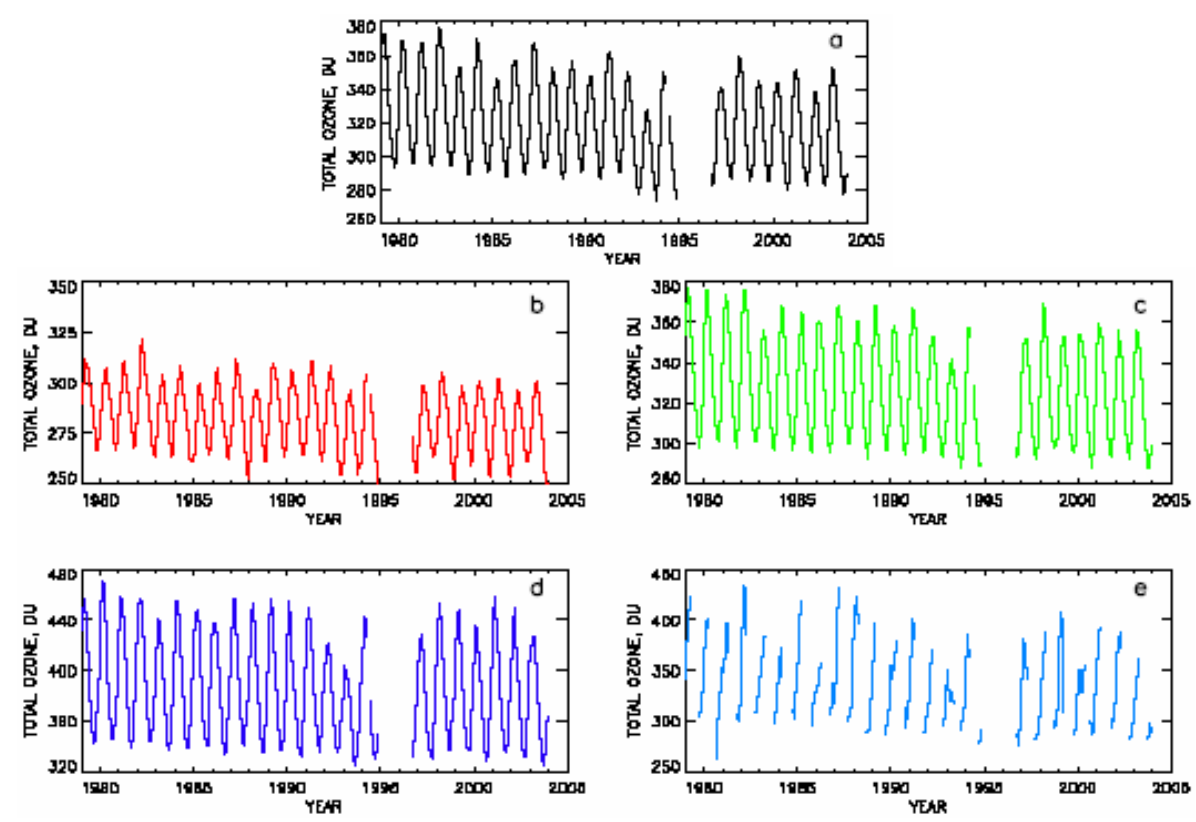

Fig. 2. Monthly mean total ozone values for the (a) zonal data, (b) tropical regime, (c) midlatitude regime, (d) polar regime, and (e) arctic regime for $25^{\circ}-60^{\circ} \mathrm{N}, 1979-2003$. Note the different scales.

statistically significant difference in the relative areas of each regime between the two runs, and no significant relative area trends were identified. It is concluded that long-term changes in ozone do not introduce a bias in the relative area trends.

\section{Results}

In the following analysis two different monthly means for the regimes are presented. First, all of the data between $25^{\circ}$ and $60^{\circ} \mathrm{N}$ are used, corresponding to the zonal average between $25^{\circ}$ and $60^{\circ} \mathrm{N}$. If a pixel contains a boundary, its total ozone value and area are halved and assigned to the two regimes separated by the boundary. This data set will be labeled as the "zero degree" data set. Next, the regions within one pixel in both latitude and longitude of the boundaries have been excluded from the analysis. This data set will be labeled as the "one degree" data set.

Figure 2 presents the area-weighted monthly mean total ozone values obtained from the TOMS data set, for the period $1979-2003$ over the latitude range $25^{\circ}-60^{\circ} \mathrm{N}$. The monthly means shown in Fig. 2 are derived from the zero degree data set. Figure 2 a shows the monthly mean total ozone values 

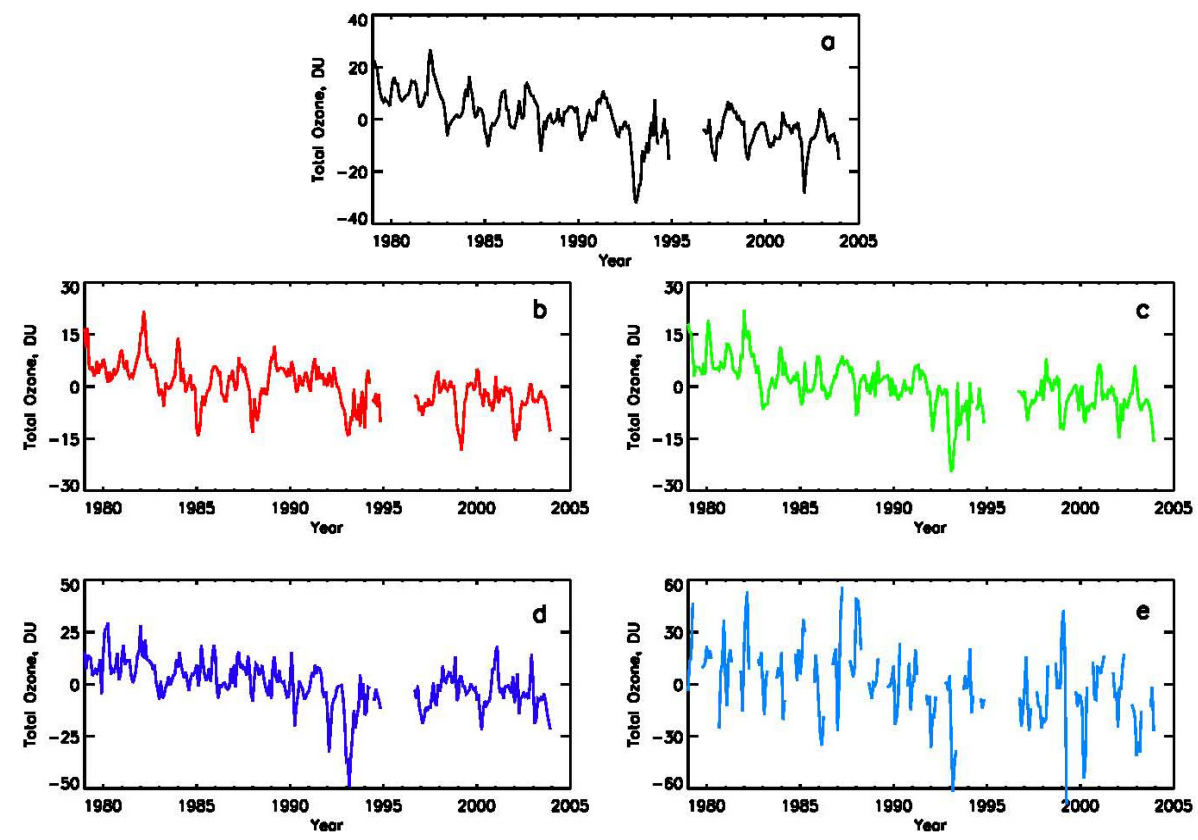

Fig. 3. Same as Fig. 2, except the monthly climatology calculated from 1979 to 2003 has been removed. Note the different scales.

Table 2. Mean total ozone values and trends for zero-degree data set.

\begin{tabular}{|c|c|c|c|}
\hline Regime & Mean (DU) & Trend per decade (DU) ${ }^{a}$ & Trend per decade (percent) ${ }^{a}$ \\
\hline Tropical & 286 & $-3.9 \pm 1.4$ & $-1.4 \pm 1.0$ \\
\hline Midlatitude & 331 & $-7.6 \pm 1.6$ & $-2.3 \pm 0.5$ \\
\hline Polar & 394 & $-11.9 \pm 3.1$ & $-3.0 \pm 0.7$ \\
\hline Arctic & 215 & $-5.2 \pm 9.0$ & $-1.5 \pm 1.2$ \\
\hline Zonal & 326 & $-10.2 \pm 2.0$ & $-3.1 \pm 0.7$ \\
\hline
\end{tabular}

a All trends calculated from January 1979 to May 1991. All errors are two-sigma.

obtained without separation into the regimes (hereinafter referred to as the "zonal data"), while Figs. 2b-e show data for the tropical, midlatitude, polar, and arctic regimes, respectively. As expected, the monthly mean total ozone values have a strong seasonal dependence. In addition, the arctic regime is not seen below $60^{\circ} \mathrm{N}$ from about May to October. In Figs. 3a-e we have plotted the data shown in Fig. 2 after the seasonal component has been removed. This deseasonalization was done by subtracting the monthly mean climatology for the 1979-2003 period. It should be noted that not all of the fluctuations seen in the deseasonalized zonal data can be found in the corresponding data for each regime. The two strong downward fluctuations seen in the zonal data in 1985 and 1988 can be seen in the tropical regime, but not in the midlatitude or polar regime. Similarly the downward fluctuation seen in 1997 is only found in the polar regime.

Linear trends and their respective errors for the zonal and regime total ozone were obtained using the statistical time se- ries model described in Stolarski et al. (2006). The time period from January 1979 to May 1991 was chosen because it is a period when the chlorine loading in the stratosphere varied almost linearly with time. The mean values for each regime and the zonal data, in addition to their trends and trend errors for the zero degree data set can be found in Table 2. All errors shown in this paper are two-sigma (95\% confidence interval). Similar results for the one degree data set can be found in Table 3. Within the experimental error there is no difference between the trends shown in the two tables. The trend in DU per decade for the zonal total ozone corresponds to a percentage trend of $-3.1 \pm 0.7$ per decade, in excellent agreement with previous estimates (WMO, 1999; Staehelin et al., 2001).

Let the areas of the tropical, midlatitude, polar, and arctic regimes between $25^{\circ}$ and $60^{\circ} \mathrm{N}$ be $\mathrm{A}_{T}, \mathrm{~A}_{M}, \mathrm{~A}_{P}$, and $\mathrm{A}_{A}$, respectively. The corresponding mean area-weighted total ozone values are defined as $\Omega_{T}, \Omega_{M}, \Omega_{P}$, and $\Omega_{A}$. Noting 
Table 3. Mean total ozone values and trends for one-degree data set.

\begin{tabular}{llll}
\hline Regime & Mean (DU) & Trend per decade (DU) $^{\mathrm{a}}$ & Trend per decade (percent) $^{\mathrm{a}}$ \\
\hline Tropical & 280 & $-3.7 \pm 2.4$ & $-1.3 \pm 1.0$ \\
Midlatitude & 333 & $-7.2 \pm 1.6$ & $-2.2 \pm 0.6$ \\
Polar & 407 & $-11.8 \pm 3.5$ & $-2.9 \pm 0.9$ \\
Arctic & 191 & $-6.3 \pm 9.4$ & $-3.2 \pm 3.8$ \\
\hline
\end{tabular}

a All trends calculated from January 1979 to May 1991. All errors are two-sigma.
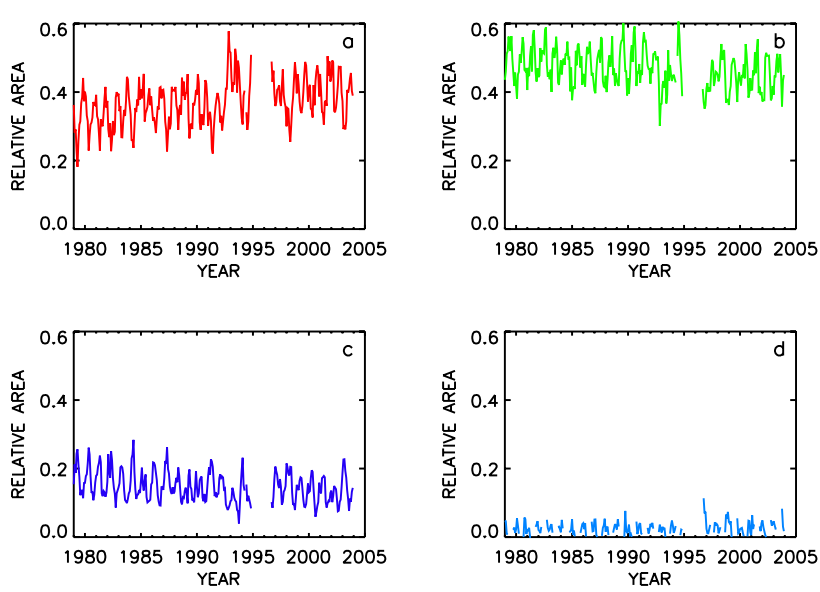

Fig. 4. Monthly mean relative areas of the (a) tropical regime, (b) midlatitude regime, (c) polar regime, and (d) arctic regime for $25^{\circ}-$ $60^{\circ} \mathrm{N}, 1979-2003$.

that $\Omega$ is the column ozone per unit area, equivalent to column mass per unit area, the total mass of ozone between $25^{\circ}$ and $60^{\circ} \mathrm{N}, \mathrm{M}$, can be written as:

$M=c A \Omega_{o}=c A_{T} \Omega_{T}+c A_{M} \Omega_{M}+c A_{P} \Omega_{P}+c A_{A} \Omega_{A}(1)$

In this equation, $A$ is the total area between $25^{\circ}$ and $60^{\circ} \mathrm{N}$, $\Omega_{O}$ is the mean of the zonal data, and $c$ is a constant of proportionality. Dividing both sides of the equation by $c A$ we get

$\Omega_{o}=R_{T} \Omega_{T}+R_{M} \Omega_{M}+R_{P} \Omega_{P}+R_{A} \Omega_{A}$

Here, the $R$ s are defined as the relative areas of the regimes. We can now examine the importance of each term on the right-hand side of Eq. (2) to the calculation of zonal total ozone.

The monthly mean relative areas derived from the TOMS data for the tropical, midlatitude, polar, and arctic regimes, between $25^{\circ}$ and $60^{\circ} \mathrm{N}$, for the period 1979-2003, are shown in Figs. $4 \mathrm{a}-\mathrm{d}$, respectively. The zero degree data set was used for all relative area analyses. The relative area for the tropical regime shows a clear increase between 1979 and 1992, and appears to level off after 1996. The relative areas of the polar and midlatitude regimes show a clear decrease between
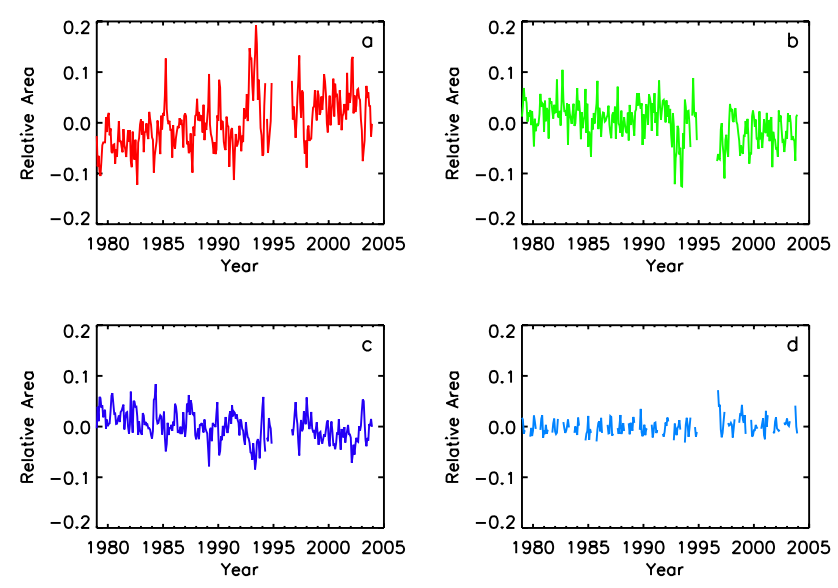

Fig. 5. Same as Fig. 4, except the monthly climatology calculated from 1979 to 2003 has been removed.

1979 and 1992, followed also by a leveling off. The results for the arctic show almost no trend, however data for this regime is only available in the winter months. Figures $5 \mathrm{a}-\mathrm{d}$ show the same data after the monthly climatology calculated between 1979 and 2003 has been removed. The mean values, trends, and trend errors for each regime can be found in Table 4 and were calculated in the same manner as for the total ozone. The regimes in which a large change in the relative area is observed are the polar and tropical regimes. Between January 1979 and May 1991, the relative area of the polar regime decreased by about $20 \%$, while that of the tropical regime increased by about $10 \%$. There was no significant change in the relative area of the midlatitude regime over this time period. These changes imply a net poleward movement of the subtropical and polar upper-troposphere fronts.

Figure 6 presents the contribution (in DU) of each term on the right hand side of Eq. (2). It should be noted that the contribution is positive for the tropical regime. This reflects the fact that the area of the tropical regime is expanding at a faster rate than the rate of decay of its mean total ozone. The contribution of the arctic regime over this period is only $0.1 \mathrm{DU}$ and shows little change with time. From January 1979 to May 1991, the polar and midlatitude regimes show net losses of 16.7, and 10.0 DU, respectively. The tropical and arctic regimes show a net gain of 11.8 , and 0.1 , 

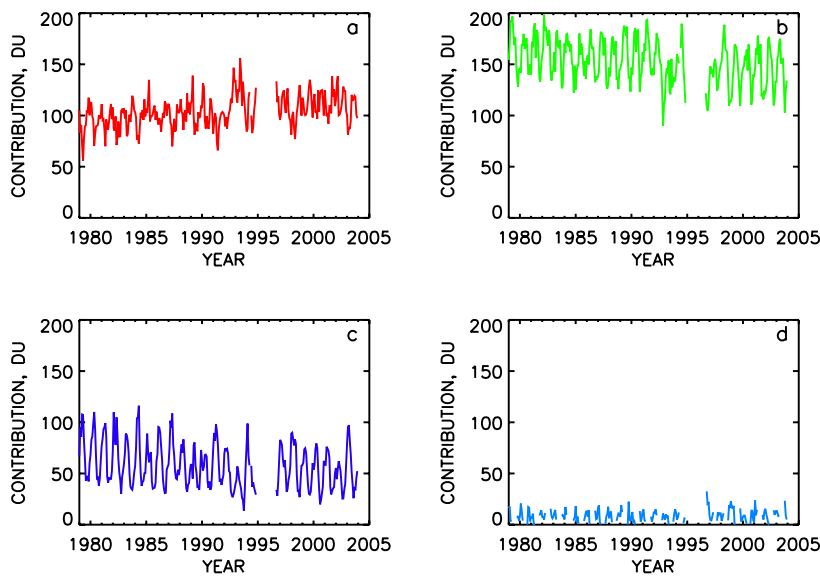

Fig. 6. Monthly mean mass contribution (in DU) by the (a) tropical regime, (b) midlatitude regime, (c) polar regime, and (d) arctic regime for $25^{\circ}-60^{\circ} \mathrm{N}, 1979-2003$.

Table 4. Mean relative areas and trends.

\begin{tabular}{lll}
\hline Regime & Mean & Trend per decade $\left(\times 10^{-2}\right)^{\mathrm{a}}$ \\
\hline Tropical & 0.35 & $2.9 \pm 1.3$ \\
Midlatitude & 0.48 & $-0.4 \pm 1.0$ \\
Polar & 0.16 & $-2.6 \pm 1.1$ \\
Arctic & 0.02 & $-0.0 \pm 0.5$ \\
\hline
\end{tabular}

a All trends calculated from January 1979 to May 1991. All errors are two-sigma.

respectively. The sum of these changes is a loss of $14.8 \mathrm{DU}$, which agrees well with the loss in the zonal ozone data of 14.9 DU over the same time period.

\section{Summary and conclusions}

A major conclusion of this paper is that the downward trend in total ozone of $3.1 \%$ per decade over the period January 1979 to May 1991, for the mid-latitude zone from $25^{\circ}-$ $60^{\circ} \mathrm{N}$, is due to a combination of (1) a net reduction of total ozone for each of the three regimes defined by Hudson et al. (2003), and (2) a change in the relative weighting among the regimes due to a net movement of the polar and subtropical fronts northward. Previous interpretations (Staehelin et al., 2001; Solomon et al., 1996, 1998) have concluded that this zonal total ozone trend was the result of increased homogeneous and heterogeneous chemistry in the stratosphere. However, other studies have argued that long-term dynamical changes could be partly or largely responsible for the ozone trend (Fusco and Salby, 1999; Graf et al., 1998). Hood et al. (1999) estimated that up to $40 \%$ of the observed midlatitude trend could be due to changes in stratospheric dynamics. In a later paper, Hood and Soukharev (2005) concluded that nonlocal EP flux variations and local PV vari-
Table 5. Terms in Eq. (3).

\begin{tabular}{lll}
\hline Regime & $\Omega \mathrm{dA} / \mathrm{dt}^{\mathrm{a}}$ & $\mathrm{A} \mathrm{d} \Omega / \mathrm{dt}^{\mathrm{a}}$ \\
\hline Tropical & 8.4 & -1.3 \\
Midlatitude & -1.3 & -3.6 \\
Polar & -10.6 & -1.7 \\
Arctic & -1.2 & -0.1 \\
Total & -3.6 & -7.0 \\
\hline
\end{tabular}

a All trends calculated from January 1979 to May 1991.

ations contributed at least $50 \%$ to observed negative trends in February near $40^{\circ}-50^{\circ} \mathrm{N}$. Statistical analyses have also shown that the Northern Hemisphere ozone trends are highly correlated with modes of variability of the atmospheric circulation, such as the Arctic Oscillation (AO), accounting for about $70-80 \%$ of the long-term ozone decline (Krzyscin et al., 2001). Reinsel et al. (2005) found the AO/AAO and EP flux index series had a considerable influence on total ozone at latitudes poleward of $40^{\circ} \mathrm{N}$. Hadjinicolaou et al. (2005) examined dynamically-driven trends in total ozone using a three dimensional chemical transport model, the transport being derived from the European Centre for Medium-Range Weather Forecasts analysis. The conclusion of their paper is that over the period 1979 to 1993 , the dynamically driven model trend accounted for $30 \%$ of the observed Northern Hemisphere negative trend, and all of the 1994-2003 positive trend. Salby and Callaghan (2002) found that most (80\%) of the changes in total ozone during the 1980s and 1990s were coherent with anomalous forcing of the upward EliassenPalm flux from the troposphere and the quasi-biennial oscillation. The remaining $20 \%$ was almost entirely accounted for by including aerosol and chlorine forcing. Koch et al. (2002) conclude that in the lower stratosphere, dynamical transport processes dominate the day-to-day as well as the interannual variability of mid-latitude ozone.

Equation (2) can be differentiated with respect to time to yield:

$$
\begin{aligned}
\frac{d \Omega}{d t}= & \frac{d \Omega_{T}}{d t} R_{T}+\frac{d R_{T}}{d t} \Omega_{T}+\frac{d \Omega_{M}}{d t} R_{M}+\frac{d R_{M}}{d t} \Omega_{M} \\
& +\frac{d \Omega_{P}}{d t} R_{P}+\frac{d R_{P}}{d t} \Omega_{P}+\frac{d \Omega_{A}}{d t} R_{A}+\frac{d R_{A}}{d t} \Omega_{A}
\end{aligned}
$$

The variation of total ozone with time for each regime is represented by two terms, one in which the total ozone is fixed and the area changes, and the other in which the area remains constant but the total ozone value changes. The results for each of the terms shown in Eq. (3) are given in Table 5. The mean values and slopes used to calculate each term in Eq. (3) can be found in Tables 2 and 4. The sum of the terms when the area remains constant is $-7.0 \mathrm{DU}$ and the sum when the total ozone remains constant is $-3.6 \mathrm{DU}$. Thus from this analysis, we would conclude that about $35 \%$ of the observed total ozone trend between January 1979 and May 
1991 is due to the northward movement of the fronts. The remaining $65 \%$ is due to changes within each regime. These changes can be the result of chemical processes and/or dynamical mechanisms, such as a net strengthening or weakening of the Brewer-Dobson circulation (Randel et al., 2002). The analysis was also repeated for the period from 1996 to 2003 , however, the errors in the constants became much larger, and no significant conclusion could be drawn for this time period.

The relative areas discussed above can be used to calculate the mean latitude of the subtropical and polar fronts for the latitude range from $25^{\circ}$ to $60^{\circ} \mathrm{N}$. A linear fit of the resulting mean latitudes from 1979 to 2003 yields a mean latitude shift northward of about one degree per decade for the subtropical front, and 0.5 degrees per decade for the polar front. It should be noted that significant portions of the polar regime, and therefore the polar front, are located above $60^{\circ} \mathrm{N}$ at certain times of the year, and parts of the subtropical front are frequently found above $60^{\circ} \mathrm{N}$ in the summer months. Hence these estimates given above cannot be representative of the entire front. When the period of study was limited to January 1979 to May 1991, then the trend for the subtropical front was 1.1 degrees per decade and the polar front was 1.2 degrees per decade. In a recent article, Fu et al. (2006) present an analysis of global measurements of atmospheric temperature based on satellite-borne microwave sounding unit (MSU) data. They conclude that the jet streams moved northward approximately 1 degree over the period from 1979 to 2005 , in essential agreement with our findings.

As shown above, the change in the zonal total ozone at mid-latitudes (between $25^{\circ}$ and $60^{\circ} \mathrm{N}$ ) is a combination of changes in total ozone within each regime, and changes in the relative areas of the regimes brought about by a net northward movement of the subtropical and polar fronts. There is considerable interest in how the total ozone at mid-latitudes will change in the future as the amount of chlorine compounds in the stratosphere decreases as a result of the Montreal protocol. The most important factor in making an accurate estimate of when and how mid-latitude total ozone will return to a pre-1979 value is the understanding of the mechanisms responsible for the movement of the upper troposphere fronts.

Acknowledgements. The early part of this work was supported by a subcontract from Orbital Sciences Corporation as part of a contract issued by the National Polar Orbiting Environmental Satellite System Inter-agency Project Office. M. Andrade was supported from a grant from the National Polar Orbiting Environmental Satellite System Inter-agency Project Office through NOAA National Environment Satellite Data Information Service, and M. Follette was supported by a grant from the NASA Science Mission Directorate. We wish to thank S. Frith for many helpful discussions on the statistical methods used in this paper. We also wish to thank a reviewer, N. Harris, and the editor, G. Vaughan, for their insightful comments which noticeably improved the original manuscript.
Edited by: G. Vaughan

\section{References}

Bluestein, H. B.: Synoptic-Dynamic Meteorology in Midlatitudes, 448 pp., Oxford University Press, New York, 1993.

Brasseur, G. and Solomon, S.: Aeronomy of the Middle Atmosphere, 441 pp., D. Reidel Publishing Company, Dordrecht, Holland, 1984.

Douglass, A. R., Weaver, C. J., Rood, R. B., and Coy, L.: A threedimensional simulation of the ozone annual cycle using winds from a data assimilation system, J. Geophys. Res., 101, 14631474, 1996.

Fioletov, V. E., Bodeker, G. E., Miller A. J., McPeters R. M., and Stolarski, R.: Global and zonal total ozone variations estimated from ground-based and satellite measurements: 1964-2000, J. Geophys. Res., 107, 4647-4660, 2002.

Fu, Q., Johanson, C. M., Wallace, J. M., and Reichler, T.: Enhanced mid-latitude upper tropospheric warming in satellite measurements, Science, 312, 1179, 2006.

Fusco, A. C. and Salby, M. L.: Interannual variations of total ozone and their relationship to variations of planetary wave activity, J. Climate, 12, 1619-1629, 1999.

Graf, H.-F., Kirchner, I., and Perlwitz, J.: Changing lower stratospheric circulation: The role of ozone and greenhouse gases, J. Geophys. Res., 103, 11 251-11 262, 1998.

Hadjinicolaou, P., Pyle, J. A., and Harris, N. R. P.: The recent turnaround in stratospheric ozone over the northern middle latitudes: A dynamical modeling perspective, Geophys. Res. Lett., 32, L12821, doi:10.1029/2005GL022476, 2005.

Harris, N. R. P., Ancellet, J., Bishop, L., Hofmann, D. J., Kerr, J. B., McPeters, R. D., Prendez, M., Randell, W. J., Staehelin, J., Subkharaya, R. H., Volz-Thomas, A., Zawodny, J., and Zerefos, C.: Trends in stratospheric and free tropospheric ozone, J. Geophys. Res., 102, 1571-1590, 1997.

Harris, N. R. P., Hudson, R. D., and Phillips, C. (Eds.): Assessment of trends in the vertical distribution of ozone, SPARC/IOC/GAW Report No. 1, 289 pp., World Meteorological Organization Global Ozone Research and Monitoring Project, Rep. 43, Geneva, 1998.

Hood, L., Rossi, S., and Beulen, M.: Trends in lower stratospheric zonal winds, Rossby wave breaking behavior, and column ozone at northern midlatitudes, J. Geophys Res., 104, 24 321-24 340, 1999.

Hood, L. L. and Soukharev, B. E.: Interannual variations of total ozone at northern midlatitudes correlated with stratospheric EP flux and potential vorticity, J. Atmos. Sci., 62, 3724-3740, 2005.

Hudson, R. D., Frolov, A., Andrade, M., and Follette, M. B.: The total ozone field separated into meteorological regimes. Part I: Defining the regimes, J. Atmos. Sci., 60, 1669-1677, 2003.

Kalnay, E., Kanamitsu, M., Kistler, R., Collins, W., Deaven, D., Gandin, L., Iredell, M., Saha, S., White, G.,Woollen, J., Zhu, Y., Chelliah, M., Ebisuzaki, W., Higgins, W., Janowiak, J., Mo, K. C., Ropelewski, C., Wang, J., Leetmaa, A., Reynolds, R., Jenne, R., and Joseph, D.: The NCEP/NCAR 40-year reanalysis project, Bull. Am. Meteor. Soc., 77, 437-471, 1996.

Koch, G., Wernli, H., Staehelin, J., and Peter, T.: A lagrangian analysis of stratospheric ozone variability and long term trends above 
Payerne (Switzerland) during 1970-2001, J. Geophys. Res., 107, 4373-4386, 2002.

Krzyscin, J. W., Degorska, M., and Rajewska-Wiech, B.: Impact of interannual meteorological variability on total ozone in northern middle latitudes: A statistical approach, J. Geophys. Res., 106, 17 953-17 960, 2001.

McPeters, R. D., Bhartia, P. K., Krueger, A. J., Herman, J. R., Schlesinger, B. M., Wellemeyer, C. G., Seftor, C. J., Jaros, G., Taylor, S. L., Swissler, T., Torres, O., Labow, G., Byerly, W., and Cebula, R. P.: Nimbus-7 Total Ozone Mapping Spectrometer (TOMS) data products user's guide, NASA Reference Publication 1384, 1996.

Reinsel, G. C., Miller, A. J., Weatherhead, E. C., Flynn, L. E., Nagatani, R. M., Tiao, G. C., and Wuebbles, D. J.: Trend analysis of total ozone data for turnaround and dynamical contributions, J. Geophys. Res., 110, D16306, doi:10.1029/2004JD004662, 2005.

Salby, M. L. and Callaghan, P. F.: Fluctuations of total ozone and their relationship to stratospheric air motions, J. Geophys. Res., 98, 2715-2727, 1993.

Salby, M. L. and Callaghan, P. F.: Interannual changes of the stratospheric circulation: relationship to ozone and tropospheric structure, J. Climate, 15, 3673-3685, 2002.

Solomon, S., Portmann, R. W., Garcia, R. R., Thomason, L. W., Poole, L. R., and McCormick, M. P.: The role of aerosol variations in anthropogenic ozone depletion at northern midlatitudes, J. Geophys. Res., 101, 6713-6727, 1996.
Solomon, S., Portmann, R. W., Garcia, R. R., Randel, W. F., Wu, F., Nagatani, R., Gleason, J., Thomason, L. W., Poole, L. R., and McCormick, M. P.: Ozone depletion at mid-latitudes: Coupling of volcanic aerosols and temperature variability to anthropogenic chlorine, Geophys. Res. Lett., 25, 1871-1874, 1998.

Staehelin, J. N., Harris, R. P., Appenzeller, C., and Eberhard, J.: Ozone trends: A review, Rev. Geophys., 39, 231-290, 2001.

Stolarski, R. S. and Frith, S. M.: Search for evidence of trends slowdown in the long-term TOMS/SBUV total ozone data record: the importance of instrument drift uncertainty, Atmos. Chem. Phys., 6, 4057-4065, 2006, http://www.atmos-chem-phys.net/6/4057/2006/.

Wellemeyer, C. G., Bhartia, P. K., McPeters, R. D., Taylor, S. L., and Ahn, Ch.: A new release of data from the Total Ozone Mapping Spectrometer (TOMS), available at http://www.aero. jussieu.fr $/ \sim$ sparc, SPARC Newsletter, 22, 37-38, 2004.

Wohltmann, I., Rex, M., Brunner, D., and Mader, J.: Integrated equivalent latitude as a proxy for dynamical changes in ozone column, Geophys. Res. Lett., 32, L09811, doi:10.1029/2005GL022497, 2005.

World Meteorological Organization: Scientific Assessment of Ozone Depletion 1998, 496 pp., Global Ozone Research and Monitoring Project Rep. 44, Geneva., 1999.

World Meteorological Organization: Scientific Assessment of Ozone Depletion 2002, 498 pp., Global Ozone Research and Monitoring Project Rep. 47, Geneva., 2003. 